\title{
Whether Hospital Accreditation Has Led to Improvement of Care Quality in Iran or not?
}

\author{
Mohammadkarim Bahadori ${ }^{*}$, Seyed Mojtaba Hosseini ${ }^{2}$ \\ ${ }^{1}$ Health Management Research Center, Baqiyatallah University of Medical Sciences, Tehran, Iran \\ ${ }^{2}$ Department of Health Services Management, Tehran North Branch, Islamic Azad University, Tehran, Iran
}

*Corresponding Author: Mohammadkarim Bahadori, Associate Professor, Ph.D. in Health Services Management, Health Management Research Center, Baqiyatallah University of Medical Sciences, Tehran, Iran. Tel: +98-021-

82482416; Email: m.bahadori@bmsu.ac.ir

Received December 26, 2016; Accepted February 8, 2017; Online Published February 21, 2017

$\mathrm{T}$ The most important mission of hospitals is to provide appropriate and high quality care for patients. Different methods and models have been used to assess the quality of care. One conventional model used recently in many countries is the accreditation model which has been efficient in developing structural, process, and outcome standards. Accreditation is a systematic process carried out based on predetermined standards for evaluating the performance of hospitals. ${ }^{1,2}$ With the recent implementation of the hospital accreditation model in Iran, whether the accreditation has improved the quality of care is under question.

Since its implementation, several studies in many countries have investigated the accreditation program and its related issues; however, there is too little evidence to make a general conclusion, and more studies are necessary. There are many contradictions in the experts' opinions of the accreditation and financial and organizational effects, program evaluation, and measurement of quality. Greenfield conducted a systematic review on accreditation and came to the conclusion that, although accreditation has currently been accepted as an essential element in improving quality of care in many parts of the world, the evidence supporting it is insufficient. Many countries have studied this issue and found no evidence for the effect of accreditation on improving quality or the evaluation of the effectiveness of the system or the various methods of implementing the program. ${ }^{3}$ The fact is that there is too little evidence to judge in the world, and the situation is the same for Iran. It is still not possible to answer the question of whether accreditation leads to improved quality of care. The various aspects of accreditation must be assessed by studies in Iran so that it can be judged correctly.

Following are some suggestions for areas to be studied in Iran:

- The effectiveness of accreditation on the quality of healthcare from the viewpoints of all stakeholders

- The relationship between accreditation and indicators of hospital performance
- The disadvantages of accreditation from the viewpoints of all stakeholders

- Evaluation of the barriers to implementation of accreditation standards in hospitals

- Evaluation of the effects of an accreditation program on patient satisfaction

- The impact of an accreditation program on indicators of patient safety

- Assessment of assessor competence in an accreditation program

- Evaluation of the effect of an accreditation program on the duration of patient hospitalization

- Assessment of the accreditation program from the viewpoint of health experts.

\section{Authors' Contributions}

$\mathrm{MB}$ and SMH contributed equally in the preparation of this paper.

\section{Conflict of Interest Disclosures}

None.

\section{Ethical Approval}

Not applicable.

\section{Acknowledgments}

The author would like to thank the "Clinical Research Development Unit" of Baqiyatallah Hospital for their kind cooperation.

\section{References}

1. Bahadori M, Teymourzadeh E, Ravangard R, Alimohammadzadeh $\mathrm{K}$. Responses to the criticisms about "The accreditation of hospitals in Iran." Iran J Public Health. 2016;45(6):840-842.

2. Bahadori M, Ravangard R, Alimohammadzadeh K. The accreditation of hospitals in Iran. Iran J Public Health. 2015;44(2):295-2956.

3. Greenfield D, Braithwaite J. Health sector accreditation research: a systematic review. Int J Qual Health Care. 2008;20(3):172-183. doi:10.1093/intqhc/mzn005.

Copyright $\odot 2017$ The Hospital Practices and Research. This is an open-access article distributed under the terms of the Creative Commons Attribution License (http://creativecommons.org/licenses/by/4.0), which permits unrestricted use, distribution, and reproduction in any medium, provided the original work is properly cited. 